\title{
Comparative Evaluation of Anthelmintic Activity of Edible and Ornamental Pomegranate Ethanolic Extracts against Schistosoma mansoni
}

\author{
Doaa A. Yones, ${ }^{1}$ Dalia M. Badary, ${ }^{2}$ Hesham M. B. Sayed, ${ }^{3}$ Soad A. H. Bayoumi, ${ }^{3}$ \\ Azza A. Khalifa, ${ }^{3}$ and Ahmed M. El-Moghazy ${ }^{3}$ \\ ${ }^{1}$ Parasitology Department, Faculty of Medicine, Assiut University, Assiut 71526, Egypt \\ ${ }^{2}$ Pathology Department, Faculty of Medicine, Assiut University, Assiut 71526, Egypt \\ ${ }^{3}$ Pharmacognosy Department, Faculty of Pharmacy, Assiut University, Assiut 71526, Egypt
}

Correspondence should be addressed to Doaa A. Yones; doaayones@gmail.com

Received 29 June 2016; Revised 14 August 2016; Accepted 30 August 2016

Academic Editor: Charles Spencer

Copyright (C) 2016 Doaa A. Yones et al. This is an open access article distributed under the Creative Commons Attribution License, which permits unrestricted use, distribution, and reproduction in any medium, provided the original work is properly cited.

\begin{abstract}
Due to the development of praziquantel (PZQ) schistosomes resistant strains, the discovery of new antischistosomal agents is of high priority in research. This work reported the in vitro and in vivo effects of the edible and ornamental pomegranate extracts against Schistosoma mansoni. Leaves and stem bark ethanolic extracts of both dried pomegranates were prepared at 100, 300, and $500 \mu \mathrm{g} / \mathrm{mL}$ for in vitro and 600 and $800 \mathrm{mg} / \mathrm{kg}$ for in vivo. Adult worms Schistosoma mansoni in RPMI-1640 medium for in vitro and S. mansoni infected mice for in vivo tests were obtained from Theodor Bilharz Research Institute, Cairo, Egypt. In vitro activity was manifested by significant coupled worms separation, reduction of motor activity, lethality, and ultrastructural tegumental alterations in adult worms. In vivo activity was manifested revealed by significant reduction of hepatic granulomas number and diameter, decreased number of bilharzial eggs in liver tissues, lowered liver inflammatory infiltration, decreased hepatic fibrosis, and inducible nitric oxide synthase (iNOS) expression. Ethanolic stem bark extract of edible pomegranate exhibited highest antischistosomal activities both in vitro and in vivo. Therefore, pomegranate showed a good potential to be used as a promising new candidate for the development of new schistosomicidal agents.
\end{abstract}

\section{Introduction}

Schistosomiasis is one of the world major public health problems, caused by the blood-dwelling fluke of the genus Schistosoma. The clinically worldwide relevant species are $S$. mansoni, S. haematobium, and S. japonicum [1]. In addition to the previously mentioned species, S. mekongi and S. intercalatum represent the most important pathogenic species for human beings. Depending on the species, the schistosome worms persist in the liver and hepatic portal system or the urinary tract system of humans. Mature schistosomes lay eggs within their host, which often get trapped in the host's tissues, resulting in inflammatory and obstructive diseases of the affected organs $[2,3]$.
Schistosomiasis is one of the most widely occurring neglected tropical diseases with high levels of incidence in Asia, Africa, and Latin America. Studies have shown approximately 779 million people living at higher risk of infection, and 239 million people are infected with schistosomes $[4,5]$.

To cure morbidity and prevent the development of severe chronic stage hepatosplenomegaly, praziquantel (PZQ) is the only choice of chemotherapy against all species of Schistosoma. Presenting good efficacy and low toxicity, the drug has been widely used for more than three decades and is therefore susceptible to the emergence of praziquantel resistant schistosomes [6].

The study of medicinal plants as a new approach for schistosomiasis treatment is feasible and promising one [7, 
8]. The research on medicinal plants is encouraged by the WHO, considering that certain traditional knowledge on curative plants could add up to the development of new pharmaceutical products as well as to the combat against diseases that affects the populations of developing countries $[9,10]$.

The search for new antischistosomal treatments has led to the study of natural substances such as artemisinin and its derivatives, curcumin, phytol, and pomegranate [11-13].

Pomegranate (Punica granatum L.) is a favorite table fruit in tropical countries, belonging to Punicaceae family. This family is unusual in having the sole genus Punica, a genus of large shrubs or small trees with two species. One is $P$. protopunica Balf. S., which is found wild in Socotra island, and the other is P. granatum L. (edible pomegranate), which is cultivated in tropical and subtropical parts of the world for its edible fruits [14].

Punica granatum L. var. nana is a dwarf variety of $P$. granatum L. popularly planted as an ornamental plant in gardens. It could well be a wild form with distinct origin. It does not usually produce edible fruits [15].

The peel and seeds of $P$. granatum L. showed various therapeutic applications such as antibacterial, antifungal, antioxidant, antitumor, antiviral, antimalarial, and antimutagenic effects $[16,17]$. Edible pomegranate extracts have been reported to have promising results against $S$. mansoni either in vitro or in vivo $[12,18,19]$.

The root, stem bark, and, to lesser extent, the fruit rind of pomegranate have been commonly used as vermifugal or taenicidal agents [20]. Pomegranate has also antiprotozoal activity and it is used in folk medicine for treatment of dysentery [21].

The methanolic extract of P. granatum L. var. nana leaves exhibited antioxidant activity, nematicidal activity against three root-knot nematode species, and hepatoprotective activity against carbon tetrachloride induced hepatotoxicity [22].

In our locality, many factors, including the high prevalence, wide distribution of schistosomiasis, and drug resistance for the already used treatment, necessitate the need for control of this helminthiasis and impulse the studies for new and more comprehensive alternative therapeutics without adverse effects. Hence, the current study aimed to investigate the in vitro and in vivo activity of leaves and stem bark ethanolic extracts of both dried edible and ornamental pomegranate against Schistosoma mansoni (Egyptian strain).

\section{Materials and Methods}

2.1. Plant Materials. $200 \mathrm{~g}$ of each of the leaves of edible pomegranate (LEP) and stem bark of edible pomegranate (SEP) (P. granatum L.) and similar leaves of ornamental pomegranate (LOP) and stem bark of ornamental pomegranate (SOP) of $P$ granatum L. var. nana was locally collected from Faculty of Pharmacy garden of medicinal plants and Experimental Station of Agriculture, Faculty of Agriculture Assiut University, Assiut, Egypt. Test plants were authenticated by Dr. Naeem E. Keltawy, Professor of Ornamental Horiculture and Floriculture, Faculty of Agriculture, Assiut University, Assiut, Egypt. Voucher specimens (number 45) were kept in the herbarium, Pharmacognosy Department, Faculty of Pharmacy, Assiut University.

2.2. Preparation of Extracts. Plant samples were allowed to dry at room temperature before being ground to fine powder. Powdered plant materials were extracted with $70 \%$ ethanol at room temperature by maceration and then filtered and the filtrates were concentrated under vacuum using rotary evaporator. The obtained solvent-free residue of each plant extract was stored at $4^{\circ} \mathrm{C}$ for subsequent preparation of the required doses.

2.3. Dose Preparations of Extracts. Plant extracts were freshly prepared before usage by suspending $1 \mathrm{~g}$ of each extract in $50 \mathrm{~mL} \mathrm{3 \%}$ tween 80 dissolved in $0.9 \%$ saline. For in vitro antischistosomal testing, 100, 300, and $500 \mu \mathrm{g} / \mathrm{mL}$ were used, while 600 and $800 \mathrm{mg} / \mathrm{kg}$ for in vivo assay were prepared [12].

2.4. Cytotoxicity Assays (CTAs) on Tissue Culture Cells. CTAs were performed on mouse fibroblast cell BALB/c 3T3 (VACSERA, Egypt) supplemented with $10 \%$ bovine calf serum, $4 \mathrm{mM}$ L-glutamine, $100 \mathrm{IU}$ penicillin, and $100 \mu \mathrm{g} / \mathrm{mL}$ streptomycin (Bioanalyse, Turkey) using the neutral red uptake assay for all pomegranate extracts at the higher concentration [23].

2.5. Evaluation of Microbial Contamination and Endotoxin Production. Total aerobic microbial count and total combined yeasts/moulds count were used for quantitative enumeration of mesophilic bacteria or fungi that may grow under aerobic conditions in all pomegranate extracts at the higher concentration and for PZQ using the pour plating technique (EDQM Council of Europe, 2014). The bacterial endotoxin test was performed by the limulus amoebocyte lysate assay (gel-clot technique) as reported by Hussaini and Hassanali [24].

2.6. Standard Antischistosomal Treatment. Praziquantel suspension, a product of Egyptian International Pharmaceutical Industries Company (EIPI Co.), was purchased locally. PZQ was used as positive control at concentration of $10 \mu \mathrm{g} / \mathrm{mL}$ for in vitro and $200 \mathrm{mg} / \mathrm{kg}$ for in vivo experiments [25, 26].

2.7. Schistosome Parasites and Experimental Infected Hosts. S. mansoni (Egyptian strain) adults were purchased from the experimental animal research unit of the Schistosome Biological Supply Center (SBSC), Theodor Bilharz Research Institute (TBRI), Cairo, Egypt. Swiss albino female mice CD strain, weighing 20-25g and aged 4 weeks, were individually infected using the tail immersion technique by exposure to a suspension containing 100 S. mansoni cercariae (100 cercariae/mouse) from naturally infected Biomphalaria alexandrina for $2 \mathrm{~h}$ according to the method described by Liang et al. [27]. Mice were bred under environmentally controlled conditions (temperature $\sim 25^{\circ} \mathrm{C}$ and $12 \mathrm{~h}$ light and 
dark cycle) and fed with a standard stock commercial pellet diet (containing $24 \%$ protein) and water ad libitum.

\section{Experimental Design}

\subsection{Experiment (1)}

3.1.1. In Vitro Assessment of the Antischistosomal Effects of the Prepared Extracts. For in vitro bioassay, Schistosoma mansoni adult worm pairs of Egyptian strain were retrieved aseptically from sacrificed infected mice and collected by perfusion of the hepatic portal system and mesenteric veins using citrated saline according to the technique of Stirewalt and Dorsey [28] from mice livers 8 weeks postinfection.

Adult worms were washed three times with the RPMI 1640 (Roswell Park Memorial Institute 1640) culture medium (Invitrogen, Carlsbad, California, USA), which was used for culturing the parasite. The medium was supplemented with L-glutamine, $20 \%$ fetal calf serum, and antibiotics $(300 \mu \mathrm{g}$ streptomycin, $300 \mathrm{IU}$ penicillin, and $160 \mu \mathrm{g}$ gentamycin per $\mathrm{mL}$ ) [12]. After washing, 5 couples of worms were transferred to each well of a 24-well culture plate (TPP, St. Louis, MO) containing the same medium.

Two $\mathrm{mL}$ of the tested doses $(100,300$, and $500 \mu \mathrm{g} / \mathrm{mL})$ from leaves and stem bark extracts was added to each well. The final volume in each well was $2 \mathrm{~mL}$. The plate was incubated at $37^{\circ} \mathrm{C}$ in a humid atmosphere containing $5 \% \mathrm{CO}_{2}$ [29]. The parasites were kept for $12 \mathrm{~h}$ and monitored every $2 \mathrm{~h}$. A pure medium and medium with $3 \%$ tween 80 in $0.9 \%$ saline were used as negative controls, while PZQ $(10 \mu \mathrm{g} / \mathrm{mL})$ was used as a positive control. All the steps were performed under a sterilized laminar flow chamber. The experiment was carried out in triplicate and repeated three times.

Treated worms were monitored for their mating (pairing) of the worms, motility (worm's motor activity changes), and mortality rate using an inverted optical microscope (Olympus CK2). Worms which did not show motility for one minute were considered dead. Changes in worm's motor activity (motility) of schistosomes were assessed qualitatively and their motor activity reduction was defined as "slight" or "significant" [30].

The effect of the treatment was also assessed with an emphasis on morphological alterations in the tegument which were observed using scanning electron microscopy (SEM) [31]. Observation of adult schistosomes in the in vitro experiment was performed at $2 \mathrm{~h}$ intervals throughout the $12 \mathrm{~h}$ experimental incubation period and the results were reported at 2, 4, 6, and $12 \mathrm{~h}$ (the end point of the experiment for the negative control groups).

3.1.2. Preparation of Adult S. mansoni Worms for SEM. To observe morphological changes in the tegument of adult parasites, schistosome worms, when they died, and control worms at $12 \mathrm{~h}$, the end point of the experiments, were washed thoroughly with distilled water. The parasites were fixed for $2 \mathrm{~h}$ in $4 \%$ glutaraldehyde ( $\mathrm{pH} 7.4$ ) and $5 \%$ paraformaldehyde in $0.1 \mathrm{M}$ cacodylate buffer ( $\mathrm{pH}$ 7.2). They were rinsed overnight in cacodylate buffer, dehydrated, dried in a critical point dryer according to Hayat [32], mounted on stubs, and sputter-coated with gold particles in the sputter coating apparatus for 6 minutes. Specimens were processed, examined, and photographed using Jeol-JSM-5400 LV at the Scanning Electron Microscope Unit, Assiut University, Assiut, Egypt.

\subsection{Experiment (2)}

3.2.1. In Vivo Assessment of the Antischistosomal Effects of the Prepared Extracts. Fifty-five S. mansoni infected female mice were obtained from TBRI, Cairo, Egypt, 8 weeks postinfection. Infected mice were randomly allocated into 11 groups with 5 animals each, at the time of the experiment:

(G1) Infected untreated control mice (negative control 1)

(G2) Infected mice given 3\% tween 80 in saline (negative control 2)

(G3) Infected mice treated with $200 \mathrm{mg} / \mathrm{kg}$ PZQ (positive control)

(G4) Infected mice treated with $600 \mathrm{mg} / \mathrm{kg}$ LEP

(G5) Infected mice treated with $600 \mathrm{mg} / \mathrm{kg}$ SEP

(G6) Infected mice treated with $800 \mathrm{mg} / \mathrm{kg}$ LEP

(G7) Infected mice treated with $800 \mathrm{mg} / \mathrm{kg}$ SEP

(G8) Infected mice treated with $600 \mathrm{mg} / \mathrm{kg}$ LOP

(G9) Infected mice treated with $600 \mathrm{mg} / \mathrm{kg} \mathrm{SOP}$

(G10) Infected mice treated with $800 \mathrm{mg} / \mathrm{kg}$ LOP

(G11) Infected mice treated with $800 \mathrm{mg} / \mathrm{kg}$ SOP

Each mouse was given a single oral dose daily for 7 consecutive days using stainless-steel esophageal tube. All mice were sacrificed by cervical dislocation after 7 days of treatment. Assessment of the treatment in vivo was performed through histopathological examination of liver tissue for detection of hepatic inflammation, hepatic fibrosis, and schistosomal granulomas formation. The assessment was also done through immunohistochemical analysis of iNOS reactivity in liver tissue. The experiment was repeated three times.

3.2.2. Histopathological Assessment. Liver samples of the left lobe of each sacrificed mouse were rinsed with phosphatebuffered saline and fixed in 10\% formalin for $24 \mathrm{~h}$. Liver samples were dehydrated in increasing concentrations of ethanol, diaphonized in xylol, and embedded in paraffin wax blocks. Sections of $4 \mu \mathrm{m}$ thickness were stained with hematoxylin and eosin [33]. The sections were evaluated using the bright field microscopy to evaluate the degree of inflammation, fibrosis, and granuloma formation followed by image capture and processing using Camidia image manager. All the granulomas found in 10 histologic sections of random fields were counted. Measurement of mean granuloma diameter was performed using an ocular micrometer at magnification of 100x. Only nonconfluent, lobular granulomas containing eggs in their centers were measured (periocular granulomas) [34]. 
3.2.3. Immunohistochemistry for Determination of iNOS Reactivity. Left lobe liver sections from the previously prepared paraffin blocks, $4 \mu \mathrm{m}$ thickness, mounted on glass slides, were kept overnight at $56^{\circ} \mathrm{C}$. They were deparaffinized with xylene and rehydrated with decreasing percentages of ethanol and finally with water. For antigen retrieval, slides were heated by microwaving in $10 \mathrm{mM}$ citrate buffer ( $\mathrm{pH} \mathrm{6.0)}$ ) for $12 \mathrm{~min}$. Slides were left to cool for $20 \mathrm{~min}$ at room temperature and rinsed with distilled water. Surroundings of the sections were marked with a PAP pen. The endogenous peroxidase activity was blocked with $\mathrm{H}_{2} \mathrm{O}_{2}$ for $10 \mathrm{~min}$ at room temperature and later rinsed with distilled water and PBS (phosphatebuffered saline). Liver sections were then incubated for $1 \mathrm{~h}$ at room temperature with the following antibody: iNOS rabbit Pab (Neomarker, RB-1605-P) antibodies. Antibodies were diluted at 1:100. The sections were washed and rinsed with PBS three times for $5 \mathrm{~min}$ each. Slides were incubated for $30 \mathrm{~min}$ at room temperature with biotinylated goat antirabbit antibodies. The streptavidin peroxidase label reagent was applied to the slides after being washed in PBS, for $30 \mathrm{~min}$ at room temperature in a humid chamber. After blotting off excess buffer, a universal staining colored product was developed by incubation with AEC (3-Amino-9Ethylcarbazole) Chromogen (Lab Vision, TA-004-HAC) for 5 min according to manufacturer's instructions. Finally, slides were dehydrated and cleared. The slides were counterstained with Mayer's hematoxylin and mounted in glycerol gelatin after washing in distilled water and mounted with cover slips [35].

3.3. Ethical Considerations. A standard protocol was drawn up in accordance with the Good Laboratory Practice (GLP) regulations of the World Health Organization (WHO). The principles of laboratory animal care were duly followed in this study [36]. Ethical animal practices were followed under standard regulations dictated by the animal care committee of Faculty of Medicine, Assiut University. Ethical approval was granted by the Research and Ethic Committee of Faculty of Medicine, Assiut University.

3.4. Statistical Data Analysis. The results were analyzed using the SPSS (Statistical Package for the Social Sciences, version 16 for Windows) software (SPSS Inc., Chicago, Illinois, USA). Significant differences were determined by one-way analysis of variance (ANOVA). The values were presented as mean \pm standard deviation $(\mathrm{SD})$. Data were analyzed using Student's Tukey's test ( $t$-test) which was used to calculate the significance of differences observed between mean values of experimental and control groups in each experiment. $P$ values of less than $0.05,0.01$, or 0.001 were used to indicate statistical significance.

\section{Results}

The preliminary phytochemical screening of both plant extracts showed the presence of volatile constituents, polyphenols glycosides, triterpenes, sterols, flavonoids, anthocyanins, triglycerides, tannins, and alkaloids.
4.1. Cytotoxicity Assays (CTAs). The optical density (OD) of each of the tested extracts was compared with the mean value $\mathrm{OD}_{540}$ for the negative control (distilled water). Tested pomegranate extracts fulfilled the mentioned acceptance criteria through absence of cytotoxic effects of the studied extracts. Cell viabilities were more than $70 \%$ relative to the negative control for tested extracts at their highest concentrations. Thus, the concentrations in which pomegranate presented the schistosomicidal activity were not associated with cytotoxic effects on fibroblast cell.

4.2. Evaluation of Microbial Contamination and Endotoxin Production. Total aerobic microbial count and total combined yeasts/moulds count were negative for the tested pomegranate extracts. Tested pomegranate extracts were endotoxin free.

4.3. In Vitro Treatment Efficacy of LEP, SEP, LOP, and SOP Extracts on Adults S. mansoni at Different Concentrations. All the tested extracts influenced the process of natural mating, causing separation of couple schistosomes depending on the concentration used and exposure time. Nearly $95 \%$ of the worms had been separated within the first $2 \mathrm{~h}$ with the use of $500 \mu \mathrm{g} / \mathrm{mL}$ SEP, compared to the negative control groups (Table 1). PZQ $(10 \mu \mathrm{g} / \mathrm{mL})$ caused couple worm separation after the first $2 \mathrm{~h}$ of incubation. Negative control groups showed couple separation nearly at $10 \mathrm{~h}$ after incubation. Moreover, concentrations which were not $100 \%$ lethal to the worms were proven as efficient mating inhibitors, once all of them separated the couples in all samples.

Concerning the motility, a significant reduction in the parasites movements was observed in all concentrations. The percentage of worms that had their motility reduced was directly proportional to the concentration and to the period of incubation. A slight decrease in motor activity was observed after $2 \mathrm{~h}$ of incubation for all adult worms exposed to 500, 300, and $100 \mu \mathrm{g} / \mathrm{mL}$ concentration of SEP. Total motility loss occurred at 4,6 , and $12 \mathrm{~h}$, respectively. No change in motor activity was observed at $4 \mathrm{~h}$ interval, while it decreased at $6 \mathrm{~h}$ interval and complete loss of motility occurred at $10 \mathrm{~h}$ interval in the negative control groups. On the other hand, PZQ $(10 \mu \mathrm{g} / \mathrm{mL})$ resulted in decrease in motor activity starting from the first $2 \mathrm{~h}$ of incubation and complete loss of motor activity in all worms occurred at $4 \mathrm{~h}$ interval.

The survival of $S$. mansoni adults exposed to ethanolic extracts of LEP, SEP, LOP, and SOP depended directly on both concentration and incubation period. The 500, 300 , and $100 \mu \mathrm{g} / \mathrm{mL}$ concentrations of SEP caused death of $100 \%$ of parasites within 4,6 , and $12 \mathrm{~h}$ of incubation, respectively (Table 1). Ethanolic extracts of LEP at 500, 300, and $100 \mu \mathrm{g} / \mathrm{mL}$ concentrations caused death of $100 \%$ worms after 6 and $12 \mathrm{~h}$ of incubation, respectively (Table 1). LOP and SOP $(500 \mu \mathrm{g} / \mathrm{mL})$ caused significant mortality $(P<$ 0.01) among schistosome parasites after $6 \mathrm{~h}$ of incubation, while 100 and $300 \mu \mathrm{g} / \mathrm{mL}$ concentrations of the same extracts expressed their mortality effect on adults $S$. mansoni after $12 \mathrm{~h}$ of incubation (Table 1). No difference was observed between male and female adult worms in response to different 


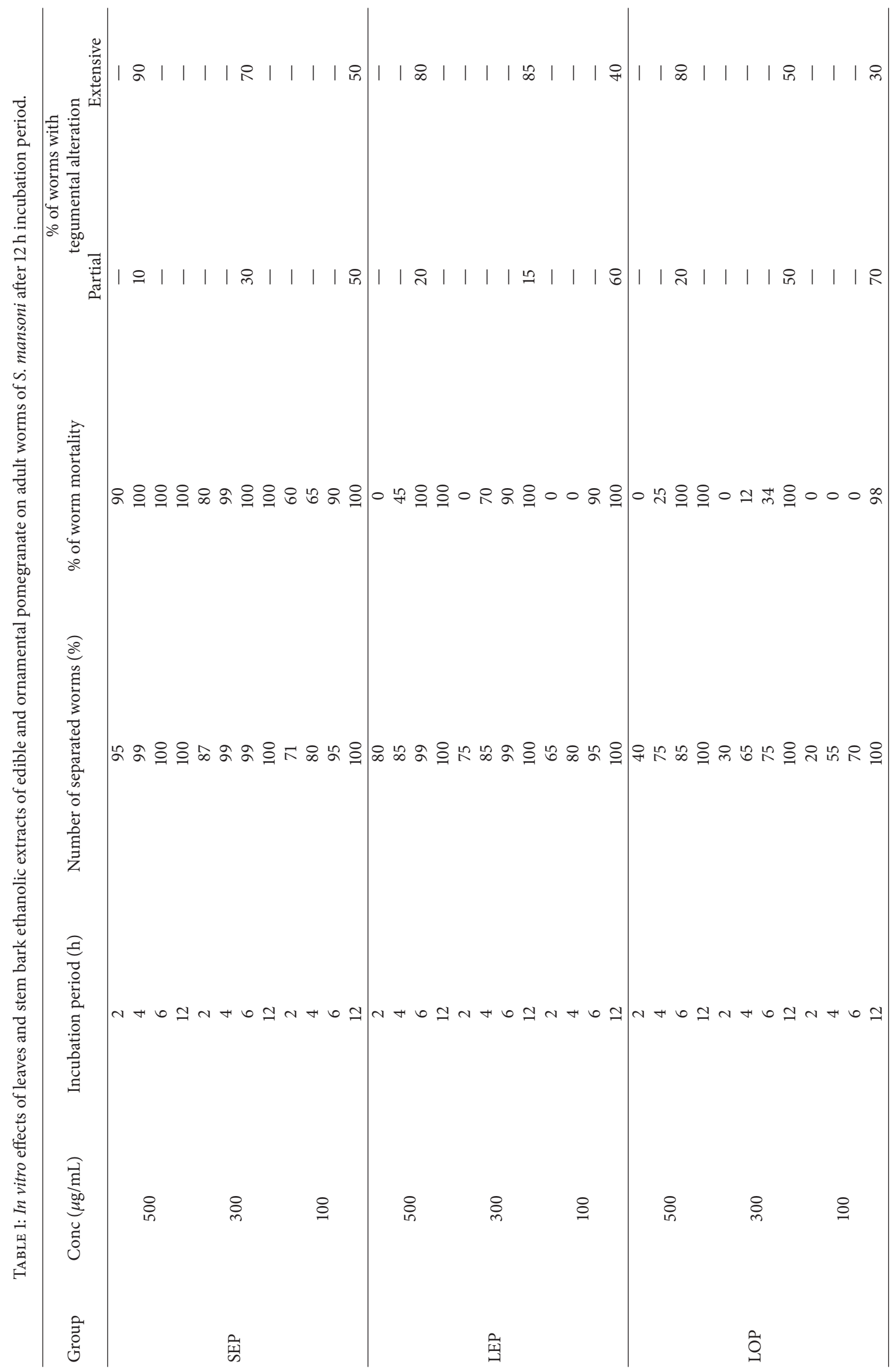




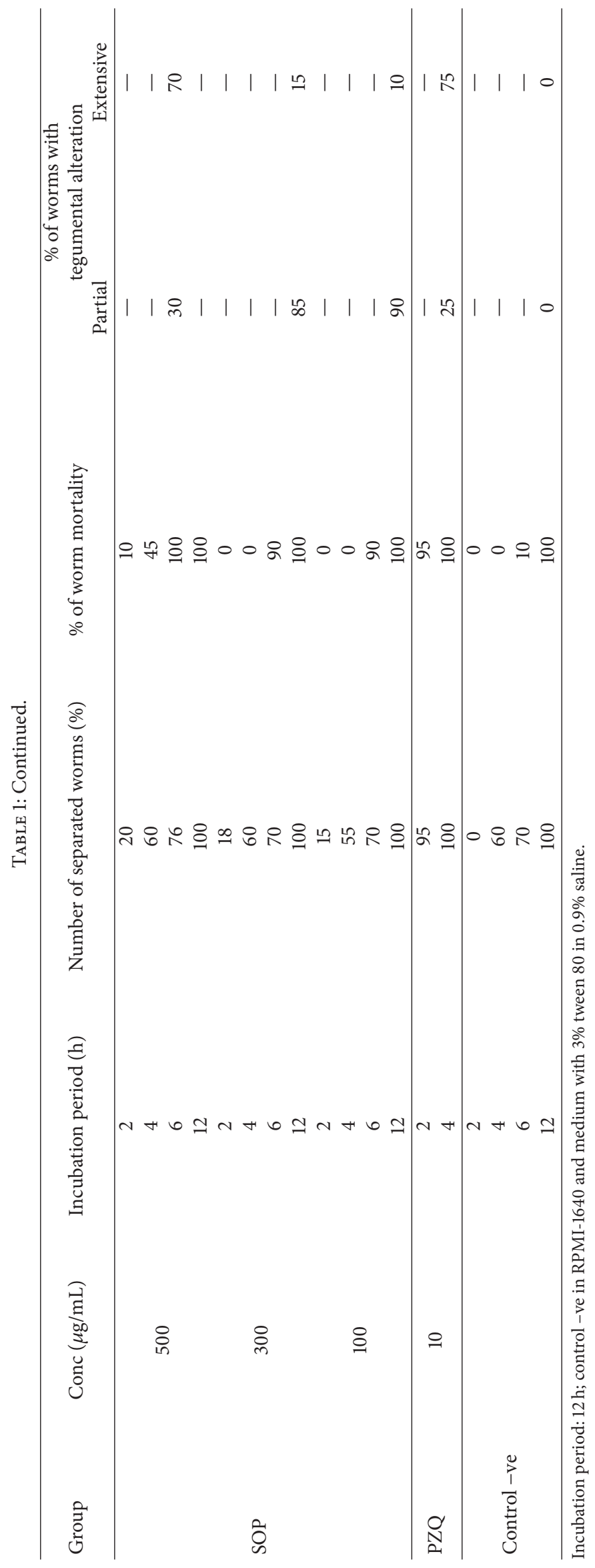




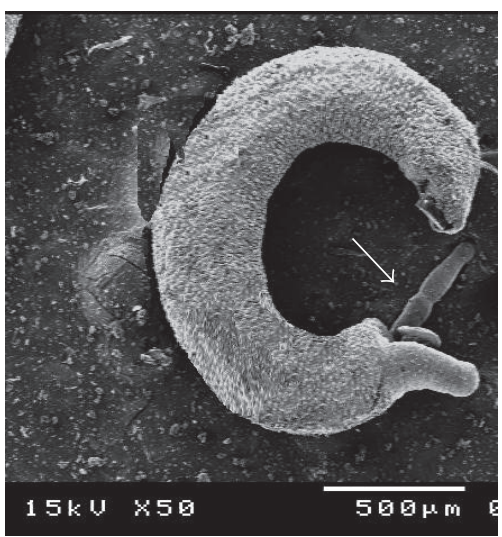

(a)

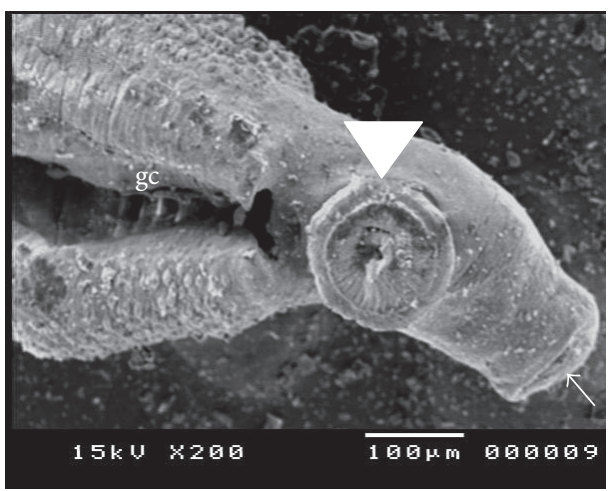

(d)

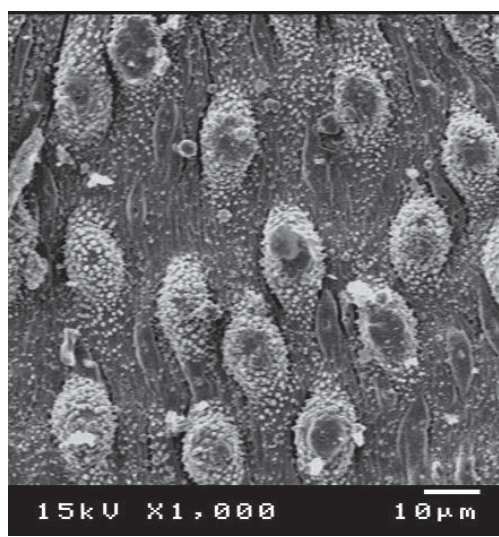

(b)

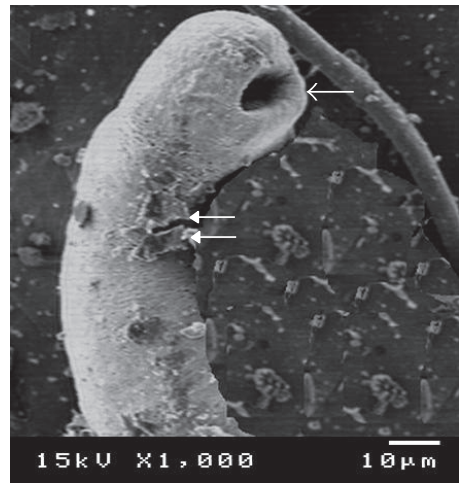

(e)

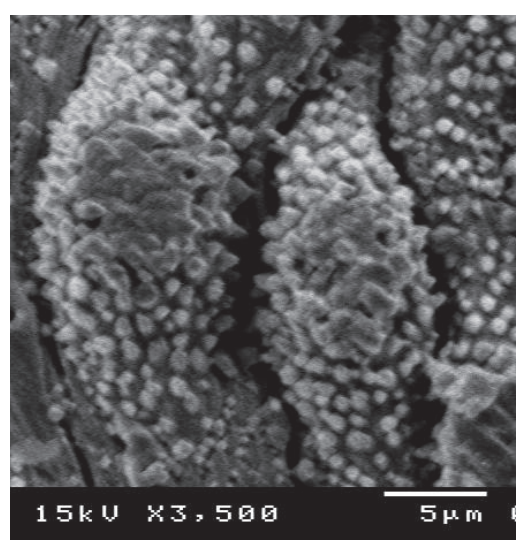

(c)

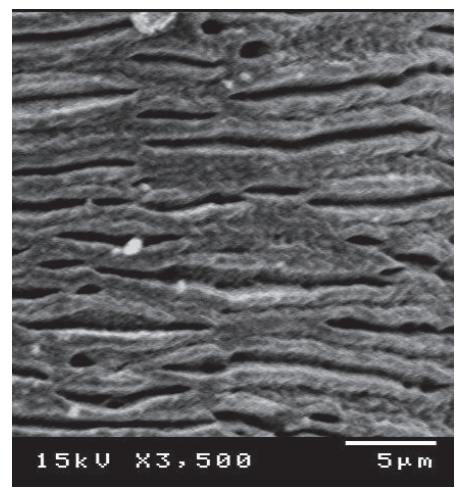

(f)

FIGURE 1: Scanning electron microscopy (SEM) of normal adult S. mansoni kept in RPMI-1640 alone or with 3\% tween 80; (a) male and female (arrow) in copula; (b) male dorsal surface showing tubercles and spines; (c) higher magnification of the tubercles and spines; (d) male anterior end showing gynecophoric canal (gc), oral sucker (arrow); and ventral sucker (arrowhead); (e) female anterior end showing oral sucker (arrow), and ventral sucker (double arrows); (f) female dorsal surface showing normal appearance of the tegument.

concentrations of the used extracts in either motility affection or survival rates.

The PZQ treated group (positive control) showed total death of the parasites (100\%) after $4 \mathrm{~h}$ of incubation (Table 1$)$. All the negative control groups were killed at $12 \mathrm{~h}$ of incubation which was considered the end point of the experiment.

4.4. Tegumental Changes of S. mansoni Adult Worms in Response to Exposure to Edible and Ornamental Pomegranate Extracts Visualized by Scanning Electron Microscope (SEM). Ultramorphological alterations were observed in S. mansoni adult males and females after $12 \mathrm{~h}$ incubation in vitro with the 100,300 , and $500 \mu \mathrm{g} / \mathrm{mL}$ concentrations of leaves and stem bark of both edible and ornamental pomegranate ethanolic extracts. The parasites exposed to LEP and SEP revealed dosedependent variable degrees of tegumental morphological alterations, when compared to negative control ones. SEP $(500 \mu \mathrm{g} / \mathrm{mL})$ induced more morphological destructions than those induced by LEP at the same dose. No tegumental changes in adult worms were observed for the negative control groups (Figure 1). The positive control (PZQ treated group) showed similar tegumental alteration in $100 \%$ of schistosome worms.
Male Worms. The treatments caused variable degrees of tegumental contractions, tubercles, and spine damage (destruction, peeling of spines, tubercles, and tegument peeling or sloughing) especially on its dorsal surface. The occurrence of bubbles surrounding the morphologically altered tubercles was observed in addition to suckers alteration or destruction (Figures 2(a)-2(d)).

The Female Worms. Tegument scaling, wrinkling, and erosion (contraction and peeling of dorsal region) and suckers' alterations or destruction were observed (Figures 2(e) and 2(f)).

Concerning treatment with LOP and SOP extracts, the worms (either male or female) showed similar morphological tegumental changes but of lesser degree to LEP and SEP induced morphological changes.

\subsection{Treatment Efficacy In Vivo of SEP, \\ LEP, LOP, and SOP Extracts}

4.5.1. Histopathological Assessment. Microscopical examination of histological liver sections from infected untreated control group revealed pathological chronic granulomatous 


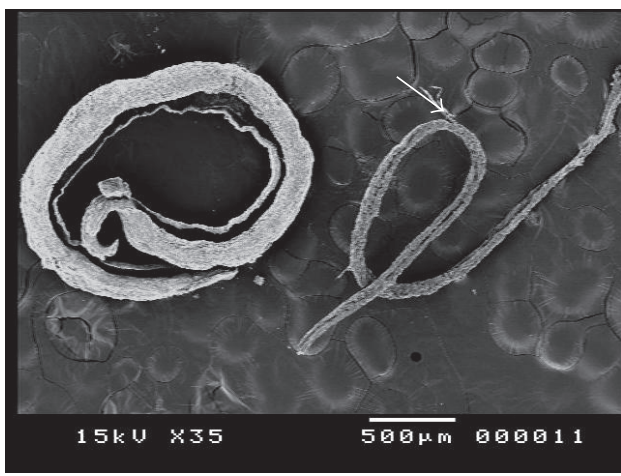

(a)

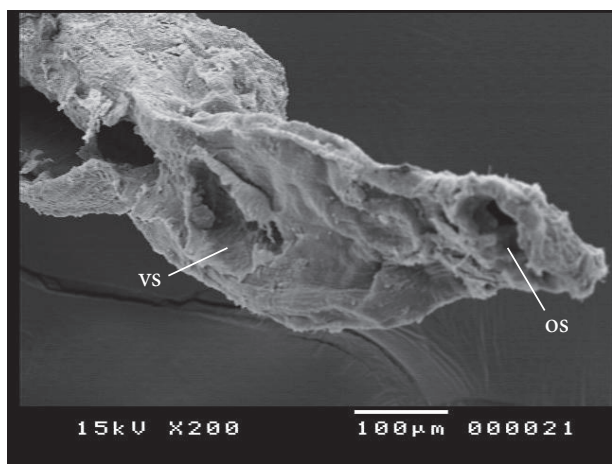

(d)

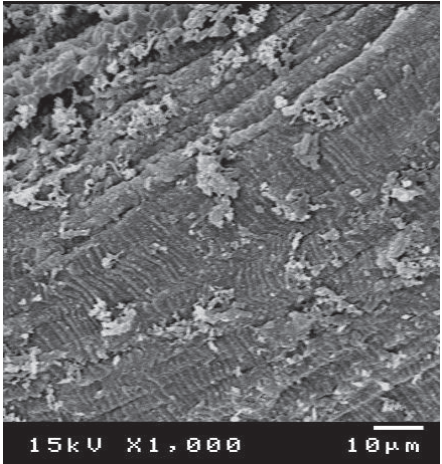

(b)

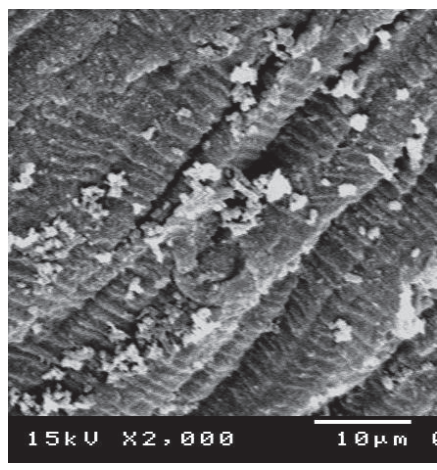

(e)

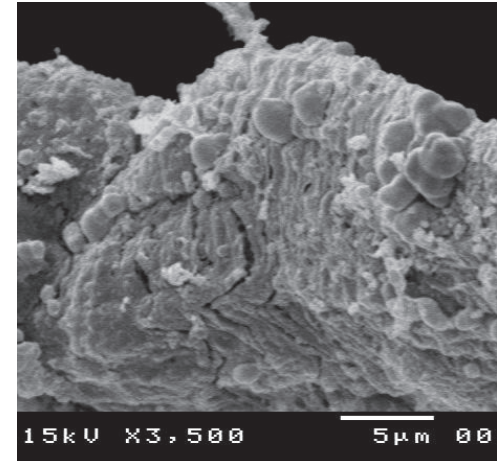

(c)

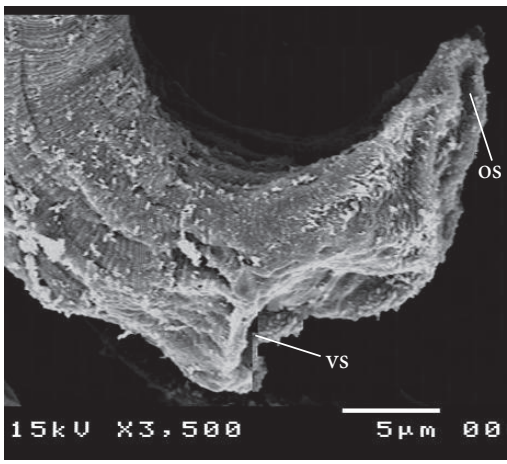

(f)

FIGURE 2: Scanning electron microscopy (SEM) of adult S. mansoni worms after their exposure to 100,300 , and $500 \mu \mathrm{g} / \mathrm{mL}$ ethanolic extracts of leaves and stem bark of edible and ornamental pomegranate. (a) Separated male and female (arrow); (b) male dorsal surface showing tegumental peeling with destruction and peeling of tubercles and spines; (c) male showing bubbles surrounding the morphologically altered tubercles on its dorsal surface; (d) male suckers' alterations or destruction, os: oral sucker and vs: ventral sucker; (e) female showing tegumental scaling, wrinkling, and erosion; (f) female suckers' alterations or destruction, os: oral sucker and vs: ventral sucker.

lesions in the hepatic parenchyma. These lesions formed of numerous bilharzial eggs containing miracidia, surrounded by numerous chronic inflammatory cells in form of epithelioid cells, lymphocytes, plasma cells, macrophages, and eosinophils forming granuloma with severe areas of fibrosis (Figure 3(a)).

Nearly similar observations were detected in the hepatic histological sections from groups treated with $600 \mathrm{mg} / \mathrm{kg}$ SOP, LOP, and LEP (Figures 3(b)-3(d)). These inflammatory reactions were less prominent in groups treated with $800 \mathrm{mg} / \mathrm{kg} \mathrm{LOP}$ and SOP in the form of granuloma with fewer eggs, less fibrosis, and moderate chronic inflammatory cell infiltration (Figures 4(a)-4(c)).

Histological liver sections from groups treated with LEP $(800 \mathrm{mg} / \mathrm{kg})$ showed moderate diffuse infiltration of liver parenchyma by chronic inflammatory cells without observed eggs or areas of fibrosis (Figure 4(d)). Similar observations were reported in histological liver sections from groups treated with 600 and $800 \mathrm{mg} / \mathrm{kg} \mathrm{SEP}$ and PZQ $(200 \mathrm{mg} / \mathrm{kg})$. They showed absence of bilharzial eggs and fibrosis with significant reduction of liver parenchyma infiltration by the chronic inflammatory cells. For hepatic granulomas number and diameter, histological liver sections from infected untreated control groups revealed about 121.3 granulomas of average diameter $235.7 \pm 16.1 \mu \mathrm{m}$. Livers of different treated groups showed decrease in granuloma size and number with minimal degenerative changes in liver tissues as shown in Table 2.

Oral administration of $800 \mathrm{mg} / \mathrm{kg}$ LEP decreased hepatic granulomas number and size to 54.1 and $37.2 \%$, respectively, while administration of $600 \mathrm{mg} / \mathrm{kg}$ of the same extract decreased them to 51.3 and $34.5 \%$, respectively. Following oral administration of $600 \mathrm{mg} / \mathrm{kg}$ SEP, there was decrease in the mean granuloma diameter to $40.1 \%$, while $800 \mathrm{mg} / \mathrm{kg}$ of the same extract showed about $40.9 \%$ reduction. Other extracts and PZQ treatments showed variable effects on hepatic granuloma number and diameter (Table 2). Thus, the hepatic granuloma average diameter was significantly smaller $(P<0.01)$ in groups treated with SEP and LEP in comparison to groups treated with SOP and LOP (600 and $800 \mathrm{mg} / \mathrm{kg}$ ) and control groups. These hepatic granuloma average diameters were nearly similar to positive control group (PZQ $200 \mathrm{mg} / \mathrm{kg}$ ) with insignificant difference $(P>$ 0.01) (Table 2).

4.5.2. Expression of iNOS Detected by Immunohistochemistry. In comparison to immunohistochemical expression of iNOS between different groups, iNOS reactivity (cytoplasmic expression) was stronger in the hepatocytes of 


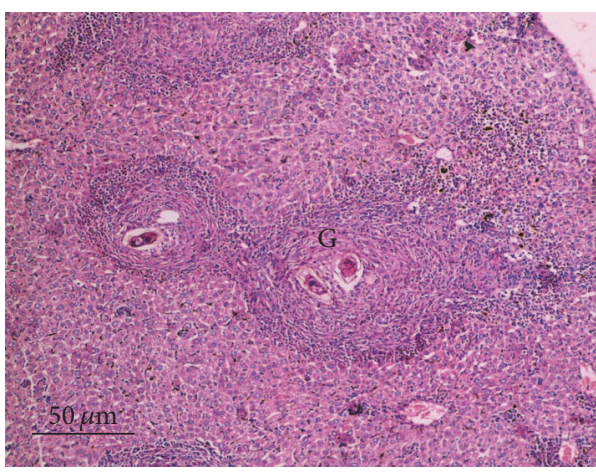

(a)

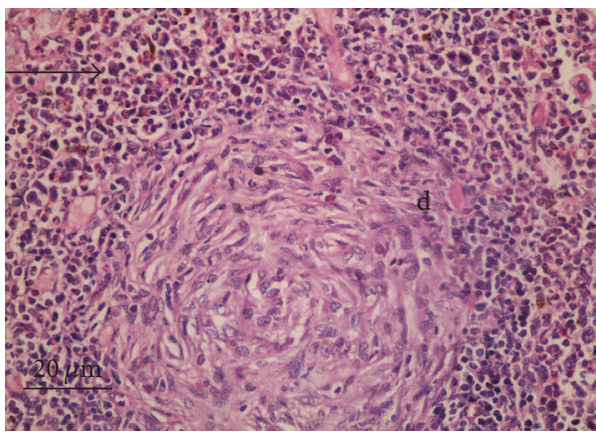

(c)

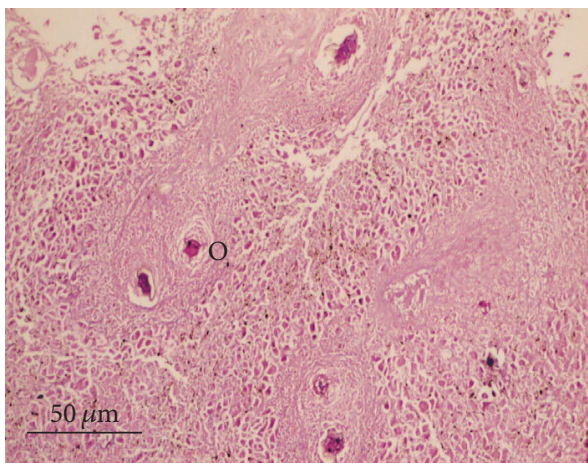

(b)

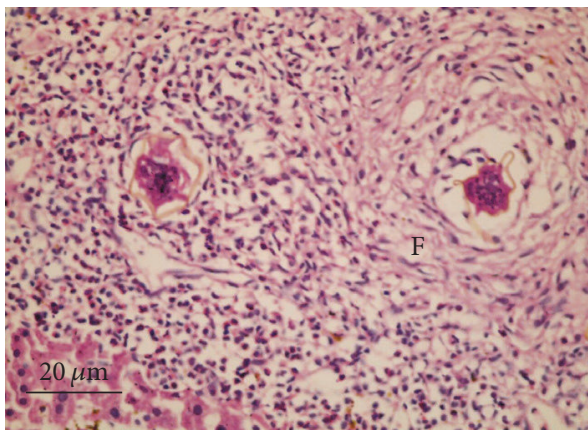

(d)

FIGURE 3: Histological liver sections; H \& E staining; (a) infected untreated group showing numerous bilharzial eggs surrounded by numerous chronic inflammatory cells $(\times 200)$; (b) group treated with $600 \mathrm{mg} / \mathrm{kg} \mathrm{SOP}(\times 200)$; (c) group treated with $600 \mathrm{mg} / \mathrm{kg} \mathrm{LOP}(\times 400)$; (d) group treated with $600 \mathrm{mg} / \mathrm{kg}$ LEP $(\times 400)$. All showed similar structures: $(\mathrm{G})$ granuloma, $(\mathrm{O})$ bilharzial eggs, and $(\mathrm{F})$ fibrosis and arrow pointed to chronic inflammatory cells.

TABLE 2: Effect of oral administration of different doses of SEP, LEP, LOP, and SOP extracts in vivo.

\begin{tabular}{|c|c|c|c|c|c|c|c|c|}
\hline \multirow[b]{2}{*}{ Group } & \multirow{2}{*}{$\begin{array}{c}\text { Dose } \\
(\mathrm{mg} / \mathrm{kg})\end{array}$} & \multicolumn{2}{|c|}{ Granuloma number } & \multicolumn{2}{|c|}{ Granuloma diameter (GD) } & \multirow{2}{*}{$\begin{array}{c}\text { Eggs in liver } \\
\text { tissue }\end{array}$} & \multicolumn{2}{|c|}{$\begin{array}{l}\text { Immunohistochemical } \\
\text { findings }\end{array}$} \\
\hline & & Mean \pm SE & Reduction $\%$ & $\begin{array}{c}\text { Mean }(\mu \mathrm{m}) \pm \\
\mathrm{SE}\end{array}$ & Reduction $\%$ & & $\begin{array}{c}\text { iNos } \\
\text { hepatocytes }\end{array}$ & $\begin{array}{c}\text { iNos } \\
\text { inflammatory } \\
\text { cells }\end{array}$ \\
\hline \multirow{2}{*}{$\begin{array}{l}\text { SEP } \\
\text { (G5\&G7) }\end{array}$} & 600 & $51.2^{* *}$ & 57.8 & $141.2 \pm 22.1^{* *}$ & 40.1 & Absent & Weakest & Negative \\
\hline & 800 & $45.3^{* *}$ & 62.7 & $139.2 \pm 24.5^{* *}$ & 40.9 & Absent & Weakest & Negative \\
\hline \multirow{2}{*}{$\begin{array}{l}\text { LEP } \\
(\mathrm{G} 4 \& \mathrm{G} 6)\end{array}$} & 600 & $59.1^{*}$ & 51.3 & $154.3 \pm 11.2^{* *}$ & 34.5 & Numerous & Strong & Strong \\
\hline & 800 & $55.7^{* *}$ & 54.1 & $148.1 \pm 22.1^{* *}$ & 37.2 & Absent & Weak & Weak \\
\hline \multirow{2}{*}{$\begin{array}{l}\text { LOP } \\
(G 8 \& G 10)\end{array}$} & 600 & $63.2^{*}$ & 47.9 & $168.1 \pm 22.1^{*}$ & 28.7 & Numerous & Strong & Strong \\
\hline & 800 & $60.8^{*}$ & 49.9 & $164.5 \pm 21.2$ & 30.2 & Few & Weak & Strong \\
\hline \multirow{2}{*}{$\begin{array}{l}\text { SOP } \\
(9 \& G 11)\end{array}$} & 600 & $68.2^{*}$ & 43.8 & $189.4 \pm 24.5^{*}$ & 19.6 & Numerous & Strong & Strong \\
\hline & 800 & $57.3^{* *}$ & 52.8 & $176.2 \pm 25.1^{*}$ & 25.2 & Few & Strong & Strong \\
\hline $\mathrm{PZQ}(\mathrm{G} 3)$ & 200 & $39.4^{*}$ & 67.6 & $135.4 \pm 20.3$ & 42.5 & Absent & Weakest & Negative \\
\hline \multicolumn{2}{|c|}{$\begin{array}{l}\text { Infected untreated controls } \\
\text { (G1\&G2) }\end{array}$} & 121.3 & - & $235.7 \pm 16.1$ & - & Numerous & Strong & Strong \\
\hline
\end{tabular}

The difference was significant at ${ }^{*} P<0.01$ and ${ }^{* *} P<0.001$ compared to infected untreated control group.

infected untreated group, group administered $3 \%$ tween 80 (Figure 5(a)), groups treated with $600 \mathrm{mg} / \mathrm{kg}$ LEP (Figure 5(d)), $600 \mathrm{mg} / \mathrm{kg}$ SOP (Figure 6(a)), $600 \mathrm{mg} / \mathrm{kg}$ LOP (Figure 6(b)), and $800 \mathrm{mg} / \mathrm{kg}$ SOP (Figure 7(a)) compared to low or weak expression in the hepatocytes of groups treated with $800 \mathrm{mg} / \mathrm{kg}$ LEP (Figure 6(c)) and $800 \mathrm{mg} / \mathrm{kg}$ LOP (Figure 6(d)) (Table 2). Groups treated with PZQ (Figure 5(c)) and 600, $800 \mathrm{mg} / \mathrm{kg}$ SEP (Figure 7(b)) revealed the lowest iNOS expression (reactivity) in the hepatocytes. The iNOS reactivity was stronger around the granulomatous 


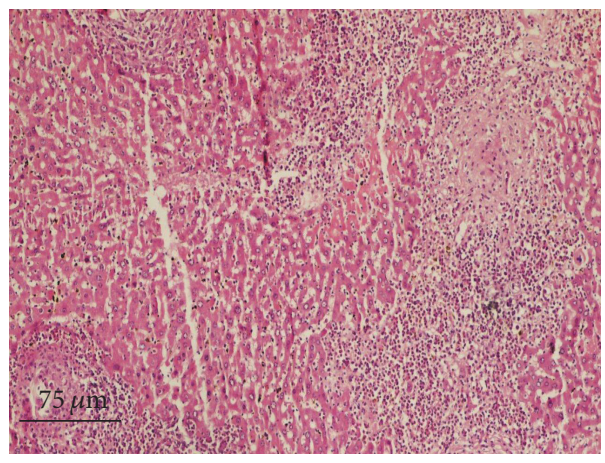

(a)

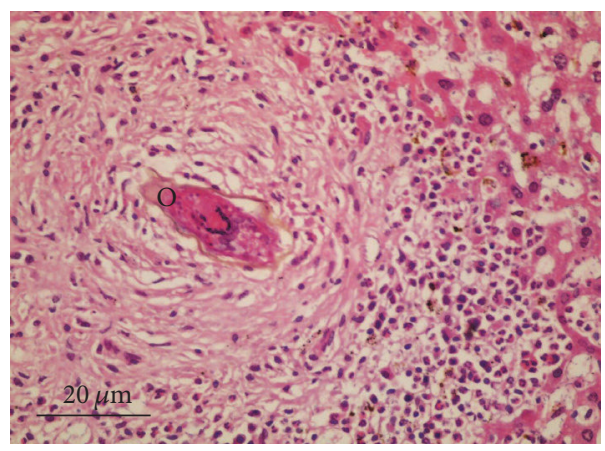

(c)

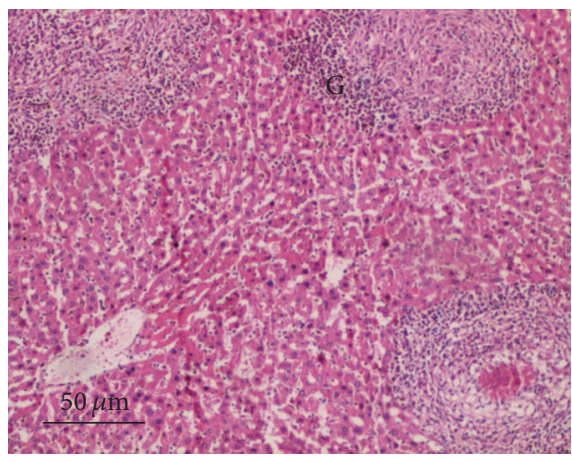

(b)

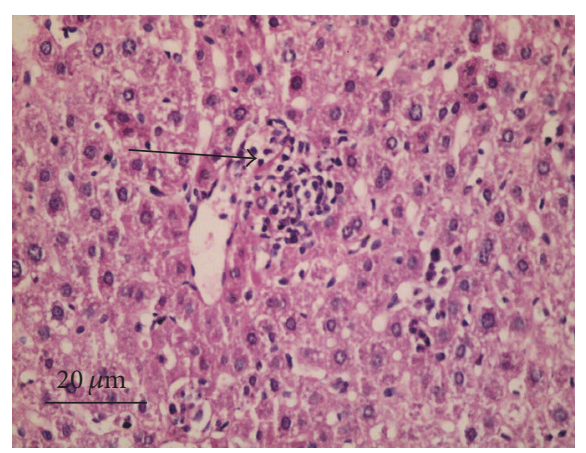

(d)

FIGURE 4: Histological liver sections; H \& E staining; (a) group treated with $800 \mathrm{mg} / \mathrm{kg} \mathrm{LOP} \mathrm{( \times 100);} \mathrm{(b)} \mathrm{group} \mathrm{treated} \mathrm{with} 800 \mathrm{mg} / \mathrm{kg}$ SOP $(\times 200)$; (c) group treated with $800 \mathrm{mg} / \mathrm{kg}$ SOP higher magnification $(\times 400)$; all showing less prominent inflammatory reactions; (d) group treated with $800 \mathrm{mg} / \mathrm{kg}$ LEP showing moderate diffuse infiltration of liver parenchyma by chronic inflammatory cells without observed eggs or areas of fibrosis $(\times 400)$; $(\mathrm{G})$ granuloma and $(\mathrm{O})$ bilharzial eggs and arrow pointed to chronic inflammatory cells.

lesions. Additionally, the iNOS reactivity reduced simultaneously with decreased granulomatous lesions.

Strong reactivity of iNOS was clearly observed in the cytoplasm of the chronic inflammatory cells in infected untreated group (Figure 5(a)), group administered 3\% tween 80 (Figure 5(b)), groups treated with $600 \mathrm{mg} / \mathrm{kg} \mathrm{LEP} \mathrm{(Fig-}$ ure 5(d)), $600 \mathrm{mg} / \mathrm{kg}$ SOP (Figure 6(c)), $600 \mathrm{mg} / \mathrm{kg}$ LOP (Figure 6(b)), $800 \mathrm{mg} / \mathrm{kg} \mathrm{LOP} \mathrm{(Figure} \mathrm{6(d)),} \mathrm{and} 800 \mathrm{mg} / \mathrm{kg}$ SOP (Figure 7(a)), compared to low or weak expression in inflammatory cells of group treated with $800 \mathrm{mg} / \mathrm{kg}$ LEP (Figure 6(a)) (Table 2). Negative reactivity of iNOS was observed in the cytoplasm of the chronic inflammatory cells in groups treated with PZQ (Figure 5(c)) and SEP (600, $800 \mathrm{mg} / \mathrm{kg}$ ) (Figure 7(b)) (Table 2).

\section{Discussion}

Plants are an important source of biologically active compounds that can provide structures for the development of new drugs [37]. In recent years, an extensive attention to natural products as a treatment of neglected tropical diseases, including schistosomiasis, has been growing. The awareness has stimulated an exertion to improve a new medicine as a substitute method to this parasitosis control $[9,10,38]$.

In this study, the effects of different concentrations of leaves and stem bark ethanolic extracts of dried edible and ornamental pomegranate against S. mansoni (Egyptian strain) were evaluated in vitro and in experimentally infected mice. This study was the first one investigating the efficacy of ornamental pomegranate against S. mansoni. Moreover, as a first step, in vitro antischistosomal studies were performed on adult worms.

In the present study, the in vitro study established the antischistosomal activity of LEP, SEP, LOP, and SOP extracts on S. mansoni adult worms concerning (mating, motility, survival time, and tegumental alterations) the worms at different concentrations $(100,300$, and $500 \mu \mathrm{g} / \mathrm{mL})$. The observed effects were dose-dependent, with $500 \mu \mathrm{g} / \mathrm{mL}$ being the most effective one in a shorter period of incubation. All the tested extracts caused unpairing of couple worms, slow contractions, motility reduction, and paralysis causing the parasites death most of the time. Noel, in his study, explained that paralysis was associated with important neurotransmitters or neuromodulators such as dopamine, acetylcholine, and/or serotonin [39].

SEP and LEP extracts were more efficient mating inhibitors than SOP and LOP extracts. SEP extract $(500 \mathrm{mg} / \mathrm{kg})$ was as effective as PZQ in vitro. Earlier studies by PicaMattoccia and Cioli [40] informed about the PZQ effects on the worms, causing contractions whenever the parasite was exposed to concentrations 0.1 and $1 \mu \mathrm{g} / \mathrm{mL}$. However, it was known that PZQ caused a quick calcium influx followed by contraction, paralysis, and tegument destruction. 


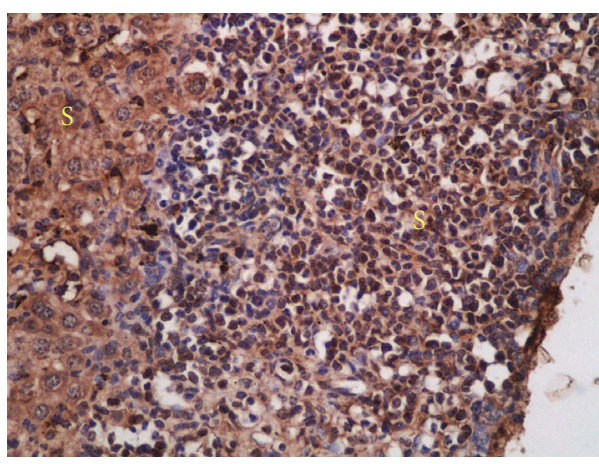

(a)

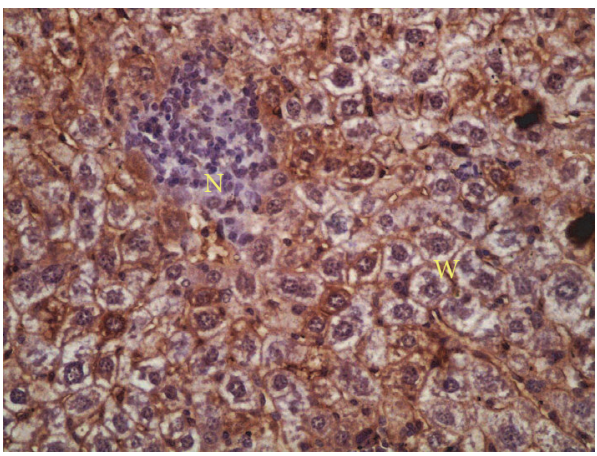

(c)

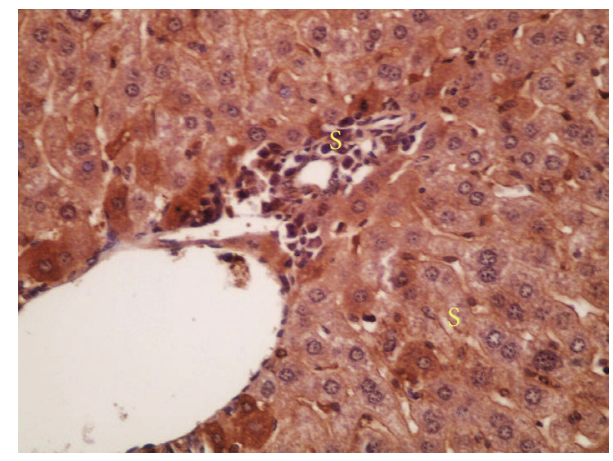

(b)

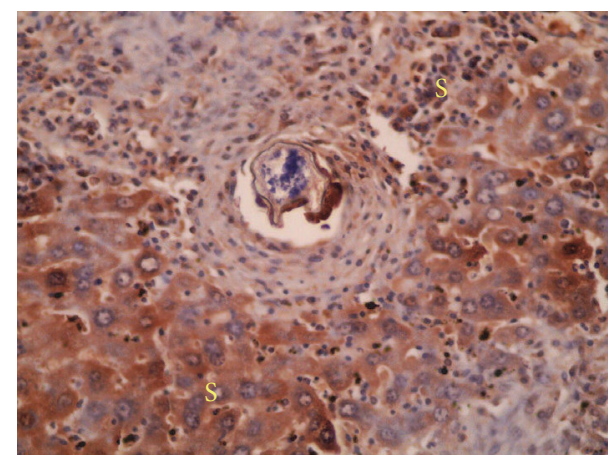

(d)

FIGURE 5: The distribution and intensity of iNOS in liver sections analyzed by immunohistochemistry; (a) infected untreated group; (b) group administered tween 80 showing strong iNOS reactivity (cytoplasmic expression) in the hepatocytes $(\times 400)$; (c) group treated with PZQ showing lowest iNOS expression (reactivity) in the hepatocytes ( $\times 400)$; (d) groups treated with $600 \mathrm{mg} / \mathrm{kg}$ LEP showing similar observation to (a) and (b) ( $\times 400)$; (S) strong, $(\mathrm{W})$ weak, and $(\mathrm{N})$ negative intensity.

The use of inverted optical microscopy did not allow detailing the tegumental changes presented in the parasite; a qualitative analysis to evaluate the tegumental damage of specimens after treatment in vitro through the scanning electron microscopy (SEM) was used in this study. SEM had been employed by several authors in order to elucidate the mechanisms of action of drugs/compounds used in the experimental treatment of schistosomiasis [9, 31, 41].

The changes induced by treatments with ethanolic extracts of dried edible and ornamental pomegranate were related to damage in suckers, oral and acetabular in both male and female schistosomes. SEM examinations of adult schistosomes showed that the treatments caused an extensive peeling of the integument especially in the dorsal region, resulting in the exposure of the antigens of this surface. Furthermore, blebs were visible on the tegument of male worms exposed to treatment with pomegranate extracts. Similar results were observed by de Oliveira et al. [9] who evaluated the in vitro effect of crude dichloromethane and aqueous fraction extracts of Baccharis trimera on S. mansoni. It is believed that the morphological changes caused by a drug/compound with schistosomicidal activity over sarcoplasmic membrane and the tegument of the parasite may be accompanied by an increasing of the exposure to antigens on the surface of the worm. These changes were identified and connected with the host immune-response, required to complement the activity of the drug. For this reason, the tegument of schistosomes had been investigated in the development of new antischistosomal drugs since the late 40 s to the present days $[9,42]$.

In the present study, the in vivo antischistosomal activity of LEP, SEP, LOP, and SOP extracts on S. mansoni infected mice was evaluated concerning histopathological changes (hepatic inflammation, schistosomal granulomas affection, and number of eggs in liver tissues) and immunological responses through determination of iNOS reactivity. The tested extracts showed dose-dependent reduction in both granuloma diameter and number, number of eggs in liver tissues, liver inflammatory infiltration, and fibrosis compared to infected untreated control groups. SEP and LEP extracts were more effective than SOP in reducing granuloma number and diameter. SEP extract showed significant reduction in inflammatory liver infiltration and hepatic fibrosis similar to PZQ. LEP showed moderate effect, while SOP and LOP extracts showed less prominent effects. The stem bark extracts (SEP and SOP) were almost better than their corresponding leaf extracts (LEP and LOP). SEP extract at the higher dose showed significant results compared to PZQ in reducing granuloma number and diameter. This reduction in the size of granulomatous inflammation indicated an anti-inflammatory effect of the used extracts. Concerning bilharzial eggs in tissues of infected animals, there was 


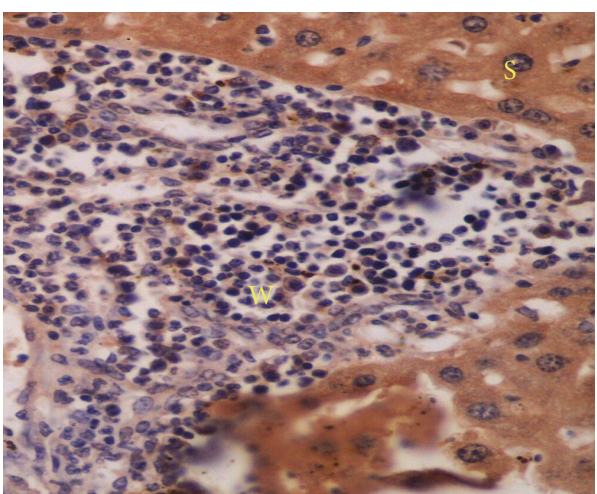

(a)

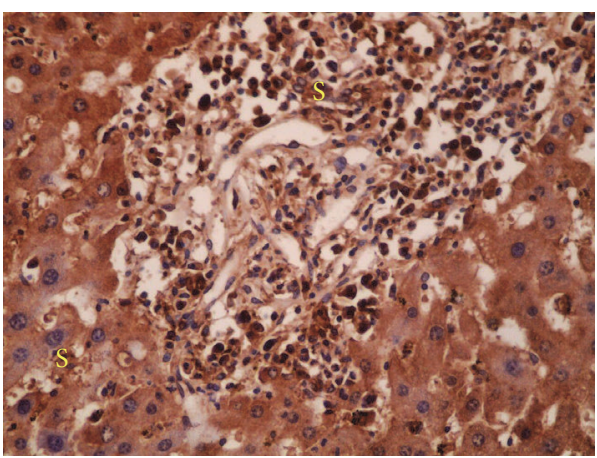

(c)

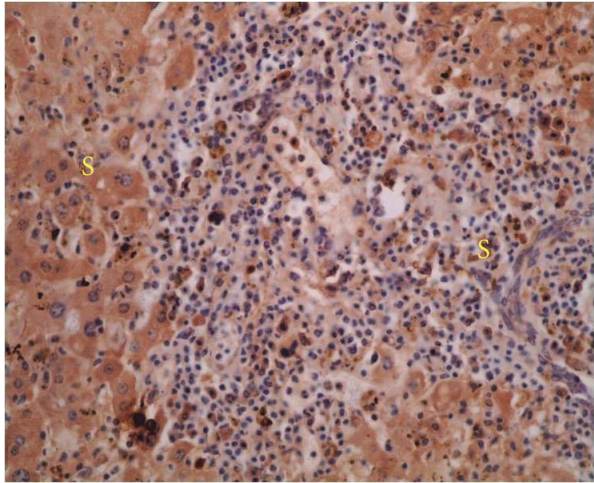

(b)

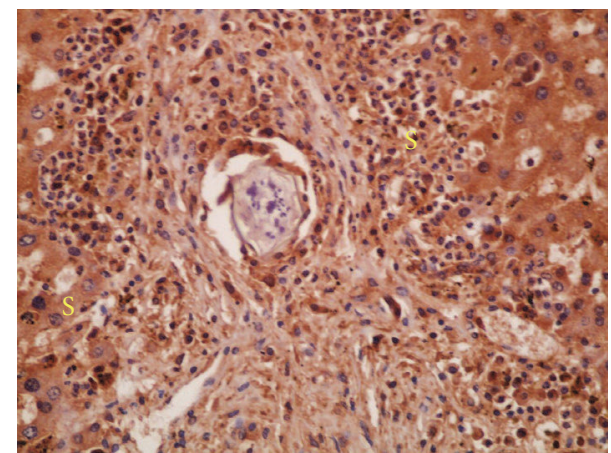

(d)

FIGURE 6: The distribution and intensity of iNOS in liver sections analyzed by immunohistochemistry; (a) group treated with $600 \mathrm{mg} / \mathrm{kg}$ SOP $(\times 400)$; (b) group treated with $600 \mathrm{mg} / \mathrm{kg}$ LOP $(\times 200)$ showing strong iNOS reactivity (cytoplasmic expression) in the hepatocytes; (c) group treated with $800 \mathrm{mg} / \mathrm{kg}$ LEP $(\times 200)$; (d) group treated with $800 \mathrm{mg} / \mathrm{kg}$ LOP $(\times 400)$ showing low or weak expression in the hepatocytes; (S) strong and $(\mathrm{W})$ weak iNOS expression.

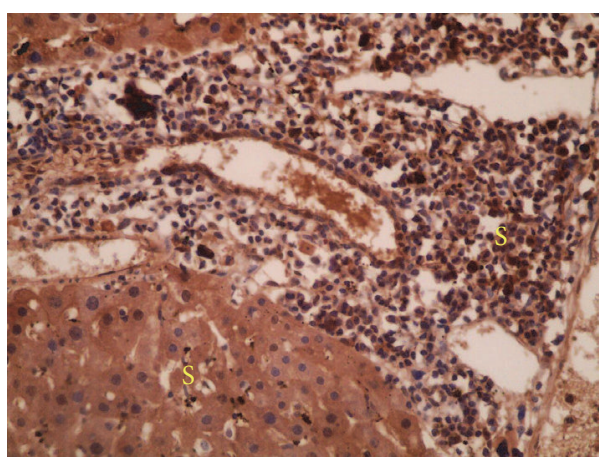

(a)

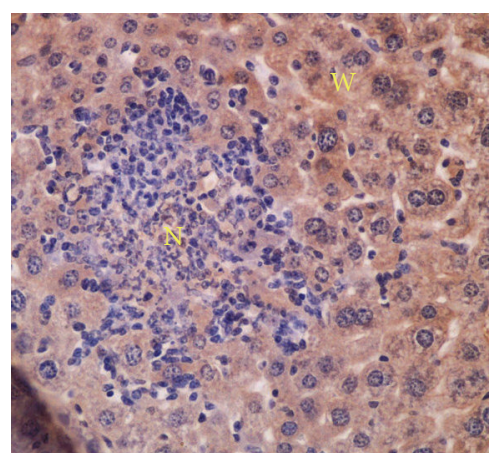

(b)

FIGURE 7: The distribution and intensity of iNOS in liver sections analyzed by immunohistochemistry; (a) group treated with $800 \mathrm{mg} / \mathrm{kg}$ SOP showing strong iNOS reactivity (cytoplasmic expression) in the hepatocytes (×200); (b) groups treated with 600 and $800 \mathrm{mg} / \mathrm{kg}$ SEP showing lowest iNOS expression (reactivity) in the hepatocytes $(\times 400)$; (S) strong, (W) weak, and $(\mathrm{N})$ negative iNOS expression.

variable response with different extracts, where LOP and SOP extracts reduced the number of eggs in the liver tissues at the higher dose, while no eggs were found in liver tissues with LEP at the same dose and SEP extracts at the lower dose compared to PZQ. Comparable results were obtained by previous trials in vitro and in vivo conducted by the other authors, using compounds isolated from Piper tuberculatum, 8-hydroxyquinoline derivatives from Artemisia annua, and Baccharis trimera that have demonstrated activity against $S$. mansoni $[8,9,43]$.

Nitric oxide (NO) is an endogenously secreted free radical, formed as a byproduct of conversion of arginine and oxygen into citrulline in an enzymatic reaction mediated by NO synthase (NOS). Three NOS isoforms have been 
described to date, inducible NOS (iNOS), which is expressed in response to proinflammatory cytokines. NO production is upregulated in response to parasitic infection. During infection with S. mansoni, there is prolonged production of large amounts of $\mathrm{NO}$, so hepatic iNOS is upregulated in Schistosoma infected mice, indicating that NO production is a part of an innate immune-response $[44,45]$. In our study, iNOS expression was measured by immunohistochemical methods either in hepatocytes or in inflammatory cells. For cytoplasmic iNOS expression in hepatocytes, it decreased with SEP, LEP, and LOP extracts compared to high expression rate in infected untreated control group, while SOP extract failed to reduce iNOS expression. SEP extract produced the highest decrease in iNOS expression at both doses used compared to PZQ group, while LEP and LOP extracts caused weak expression of iNOs at only the higher dose, so the inhibitory effect of the extracts on iNOs expression was dosedependent. Regarding iNOs expression in inflammatory cells, only SEP and LEP extracts showed inhibitory effect, where SEP abolished iNOS expression at both doses used which was comparable to PZQ group, while LEP at the higher dose caused weak expression of iNOs.

Pomegranate is of a great interest to research in pharmaceutical and new drug development fields because of its distinctive bioactivities, such as hypolipidemic, antiviral, antifungal, antineoplastic, anti-inflammatory, antimutagenic, antioxidant, antibacterial, and antidiarrheal [46-49]. Few studies investigated the effects of edible pomegranate as antischistosomal alternative and reported similar changes in the motility and in the survival rates of the parasite $[12,18,19]$

By reviewing all the available literature, no previous works came across on the use of any ornamental pomegranate extract against $S$. mansoni. Hence, the present work was the first one to prove its antischistosomal activities.

The pharmacological properties of various different parts of this plant have been attributed to its high content of bioactive secondary metabolites, such as polyphenols glycosides, triterpenes, sterols, flavonoids, anthocyanins, triglycerides, tannins, and alkaloids [20, 50].

Pomegranate and its constituents have safely been consumed for centuries without adverse effects. Studies of pomegranate constituents in animals at concentrations and levels commonly used in folk and traditional medicine did not report any toxic effects [51].

\section{Conclusion}

Ornamental and edible pomegranate extracts have in vitro and in vivo antischistosomal activity against $S$. mansoni. The in vitro activity was manifested in couple worm's separation and reduction or complete loss of motor activity and lethality and ultramorphological changes in adult worms. The in vivo activity was manifested in reduction of hepatic granulomas number and diameter, decrease of number of bilharzial eggs in liver tissues, less liver inflammatory infiltration, less hepatic fibrosis, and decreased iNOS expression, thus indicating anti-inflammatory effect. Extracts of edible pomegranate were more effective than those of ornamental pomegranate. The highest antischistosomal activity was observed for the ethanolic stem bark extract of edible pomegranate, which gave comparable results to PZQ both in vitro and in vivo. More studies are needed in order to isolate and identify pomegranate active compounds against the worm and to understand pomegranate mechanism of action on the tegument.

\section{Competing Interests}

The authors declare that there are no competing interests regarding the publication of this paper.

\section{Acknowledgments}

The authors are grateful to Dr. Mohamed A. Mokhtar, Microbiology and Immunology Department, Faculty of Medicine, Assiut University, Assiut, Egypt, for performing cytotoxicity assays and evaluation of microbial contamination and endotoxin production. They also thank Mr. Ahmed Ibrahim (Scanning Electron Microscope Unit, Assiut University) for his expert help with the SEM studies.

\section{References}

[1] N. Cowan and J. Keiser, "Repurposing of anticancer drugs: in vitro and in vivo activities against Schistosoma mansoni," Parasites \& Vectors, vol. 8, article 417, 2015.

[2] B. Gryseels, K. Polman, J. Clerinx, and L. Kestens, "Human schistosomiasis," The Lancet, vol. 368, no. 9541, pp. 1106-1118, 2006.

[3] L.-J. Song, H. Luo, W.-H. Fan et al., "Oxadiazole-2-oxides may have other functional targets, in addition to SjTGR, through which they cause mortality in Schistosoma japonicum," Parasites \& Vectors, vol. 9, article 26, 2016.

[4] WHO, "Accelerating work to overcome the global impact of neglected tropical diseases: a roadmap for implementation," 2012, http://www.who.int/neglected_diseases/NTD_RoadMap_ 2012_Fullversion.pdf.

[5] D. G. Colley, A. L. Bustinduy, W. E. Secor et al., "Human schistosomiasis," The Lancet, vol. 383, pp. 2253-2264, 2014.

[6] W. Wang, L. Wang, and Y. S. Liang, "Susceptibility or resistance of praziquantel in human schistosomiasis: a review," Parasitology Research, vol. 111, no. 5, pp. 1871-1877, 2012.

[7] S. M. Allegretti, C. N. F. de Oliveira, R. N. de Oliveira, T. F. Frezza, and V. L. G. Rehder, "The use of Brazilian medicinal plants to combat Schistosoma mansoni," in Schistosomiasis, M. B. Rokni, Ed., chapter 3, pp. 27-70, InTech, Rijeka, Croatia, 2012.

[8] J. de Moraes, C. Nascimento, L. F. Yamaguchi, M. J. Kato, and E. Nakano, "Schistosoma mansoni: in vitro schistosomicidal activity and tegumental alterations induced by piplartine on schistosomula," Experimental Parasitology, vol. 132, no. 2, pp. 222-227, 2012.

[9] R. N. de Oliveira, V. L. G. Rehder, A. S. S. Oliveira, V. D. L. S. Jeraldo, A. X. Linhares, and S. M. Allegretti, "Anthelmintic activity in vitro and in vivo of Baccharis trimera (Less) DC against immature and adult worms of Schistosoma mansoni," Experimental Parasitology, vol. 139, no. 1, pp. 63-72, 2014.

[10] J. de Moraes, "Natural products with antischistosomal activity," Future Medicinal Chemistry, vol. 7, no. 6, pp. 801-820, 2015. 
[11] L. Shaohong, T. Kumagai, A. Qinghua et al., "Evaluation of the anthelmintic effects of artesunate against experimental Schistosoma mansoni infection in mice using different treatment protocols," Parasitology International, vol. 55, no. 1, pp. 63-68, 2006.

[12] Z. H. Fahmy, A. M. El-Shennawy, W. El-Komy et al., "Potential antiparasitic activity of pomegranate extracts against shistosomules and mature worms of Schistosoma Mansoni: in vitro and in vivo study," Australian Journal of Basic and Applied Sciences, vol. 3, pp. 4634-4643, 2009.

[13] J. de Moraes, R. N. de Oliveira, J. P. Costa et al., "Phytol, a diterpene alcohol from chlorophyll, as a drug against neglected tropical disease schistosomiasis mansoni," PLoS Neglected Tropical Diseases, vol. 8, no. 1, Article ID e2617, 2014.

[14] E. Stover and E. W. Mercure, “The pomegranate: a new look at the fruit of paradise," HortScience, vol. 42, no. 5, pp. 1088-1092, 2007.

[15] M. M. Mir, I. Umar, S. A. Mir, M. U. Rehma, G. H. Rather, and S. A. Banday, "Quality evaluation of pomegranate crop-a review," International Journal of Agriculture and Biology, vol. 14, no. 4, pp. 658-667, 2012.

[16] G. Dipak, P. Axay, C. Manodeep et al., "Phytochemical and pharmacological profile of Punica granatum: an overview," International Research Journal of Pharmacy, vol. 3, pp. 65-68, 2012.

[17] M. Hajoori, M. Naik, K. Naik et al., "Evaluation of antimicrobial activity of Punica granatum peel extracts using different solvent system," International Journal of Pharmacological Screening Methods, vol. 4, pp. 26-31, 2014.

[18] K. Abozeid, M. Shohayeb, and A. Ismael, "In vitro tests for efficacy of tannins extracted from pomegranate (Punica granatum) against Schistosoma mansoni miracidia," Journal of Science and Technology, vol. 13, no. 1, pp. 55-65, 2012.

[19] G. Y. Osman, A. H. Mohamed, T. A. Salem et al., "Immunoparasitological effect of Punica granatum in Schistosoma mansoni infected mice," in Proceedings of the 10th International Conference on Future Horizon of Environmental Sustainable Development in Arab Countries and Facing the Challenges, Sharm El-Sheikh, Egypt, December 2013.

[20] C. Prakash and I. Prakash, "Bioactive chemical constituents from pomegranate (Punica granatum) juice, seed and peela review," International Journal of Research in Chemistry and Environment, vol. 1, no. 1, pp. 1-18, 2011.

[21] R. Wang, Y. Ding, R. Liu et al., "Pomegranate: constituents, bioactivities and pharmacokinetics," Fruit, Vegetable and Cereal Science and Biotechnology, vol. 4, pp. 77-78, 2010.

[22] A. M. Emam, M. A. Ahmed, M. A. Tammam et al., "Isolation and structural identification of compounds with antioxidant, nematicidal and fungicidal activities from Punica granatum L. var. nana," International Journal of Scientific \& Engineering Research, vol. 6, no. 11, pp. 1023-1040, 2015.

[23] G. Repetto, A. Del-Peso, and J. L. Zurita, "Neutral red uptake assay for the estimation of cell viability/cytotoxicity," Nature Protocols, vol. 3, no. 7, pp. 1125-1131, 2008.

[24] S. N. Hussaini and H. T. Hassanali, "Limulus amoebocyte lysate assay of endotoxin: a method for visual detection of the positive gel reaction," Journal of Medical Microbiology, vol. 24, no. 1, pp. 89-90, 1987.

[25] G. Allam and A. S. A. Abuelsaad, "In vitro and in vivo effects of hesperidin treatment on adult worms of Schistosoma mansoni," Journal of Helminthology, vol. 88, no. 3, pp. 362-370, 2014.
[26] L. Dong, W. Duan, J. Chen, H. Sun, C. Qiao, and C.-M. Xia, "An artemisinin derivative of praziquantel as an orally active antischistosomal agent," PLoS ONE, vol. 9, no. 11, Article ID el12163, 2014.

[27] Y. S. Liang, I. John, J. I. Bruce et al., "Laboratory cultivation of schistosome vector snails and maintenance of schistosome life cycles," in Proceedings of the 1st Sino-American Symposium, vol. 1, pp. 34-45, 1987.

[28] M. A. Stirewalt and C. H. Dorsey, "Schistosoma manonsi: cercarial penetration of host epidermis at the ultrastructural level," Experimental Parasitology, vol. 35, no. 1, pp. 1-15, 1974.

[29] S.-H. Xiao, J. Keiser, J. Chollet et al., "In vitro and in vivo activities of synthetic trioxolanes against major human schistosome species," Antimicrobial Agents and Chemotherapy, vol. 51, no. 4, pp. 1440-1445, 2007.

[30] J. de Moraes, A. A. C. Almeida, M. R. M. Brito et al., "Anthelmintic activity of the natural compound (+)-limonene epoxide against Schistosoma mansoni," Planta Medica, vol. 79, no. 3-4, pp. 253-258, 2013.

[31] R. N. de Oliveira, V. L. G. Rehder, A. S. S. Oliveira et al., "Schistosoma mansoni: in vitro schistosomicidal activity of essential oil of Baccharis trimera (less) DC," Experimental Parasitology, vol. 132, no. 2, pp. 135-143, 2012.

[32] M. A. Hayat, Principles and Techniques of Electron Microscopy: Biological Applications, vol. 1, Union New Jersey University Park Press, 2nd edition, 1981.

[33] C. Hirsch, C. S. Zouain, J. B. Alves, and A. M. Goes, "Induction of protective immunity and modulation of granulomatous hypersensitivity in mice using PIII, an anionic fraction of Schistosoma mansoni adult worm," Parasitology, vol. 115, no. 1, pp. 21-28, 1997.

[34] I. R. B. Aly, M. A. Hendawy, E. A. Ali, E. Hassan, and M. M. F. Nosseir, "Immunological and parasitological parameters after treatment with dexamethasone in murine Schistosoma mansoni," Memorias do Instituto Oswaldo Cruz, vol. 105, no. 6, pp. 729-735, 2010.

[35] M. R. Hussein, A. K. Haemel, and G. S. Wood, "p53-related pathways and the molecular pathogenesis of melanoma," European Journal of Cancer Prevention, vol. 12, no. 2, pp. 93-100, 2003.

[36] G. D. Ruxton and N. Colegrave, Experimental Design for the Life Sciences, Oxford University Press, New York, NY, USA, 2nd edition, 2006.

[37] L. R. S. Tonuci, N. I. Melo, H. J. Dias et al., "In vitro schistosomicidal effects of the essential oil of Tagetes erecta," Revista Brasileira de Farmacognosia, vol. 22, no. 1, pp. 88-93, 2012.

[38] J. de Moraes, "Antischistosomal natural compounds: present challenges for new drug screens," in Current Topics in Tropical Medicine, A. J. Rodriguez-Morales, Ed., pp. 333-358, InTech, Rijeka, Croatia, 2012.

[39] F. Noel, "Sistema neuromuscular e controle da motilidade do verme adulto," in Schistosoma mansoni \& Esquistossomose: Uma Visão Multidisciplinar, O. S. Carvalho, P. M. Z. Coelho, and H. L. Lenzi, Eds., pp. 207-244, FIOCRUZ, Rio de Janeiro, Brazil, 2008.

[40] L. Pica-Mattoccia and D. Cioli, "Sex- and stage-related sensitivity of Schistosoma mansoni to in vivo and in vitro praziquantel treatment," International Journal for Parasitology, vol. 34, no. 4, pp. 527-533, 2004.

[41] R. El Ridi, H. Tallima, M. Salah et al., "Efficacy and mechanism of action of arachidonic acid in the treatment of hamsters 
infected with Schistosoma mansoni or Schistosoma haematobium," International Journal of Antimicrobial Agents, vol. 39, no. 3, pp. 232-239, 2012.

[42] T. Manneck, Y. Haggenmüller, and J. Keiser, "Morphological effects and tegumental alterations induced by mefloquine on schistosomula and adult flukes of Schistosoma mansoni," Parasitology, vol. 137, no. 1, pp. 85-98, 2010.

[43] G. Allam, A. F. Eweas, and A. S. A. Abuelsaad, "In vivo schistosomicidal activity of three novels 8-hydroxyquinoline derivatives against adult and immature worms of Schistosoma mansoni," Parasitology Research, vol. 112, no. 9, pp. 3137-3149, 2013.

[44] L. R. Brunet, M. Beall, D. W. Dunne, and E. J. Pearce, "Nitric oxide and the Th2 response combine to prevent severe hepatic damage during Schistosoma mansoni infection," The Journal of Immunology, vol. 163, no. 9, pp. 4976-4984, 1999.

[45] E. M. Ali, S. M. Hamdy, and T. M. Mohamed, Nitric Oxide Synthase and Oxidative Stress: Regulation of Nitric Oxide Synthase, InTechOpen, Rijeka, Croatia, 2012.

[46] S. H. Abdollahzadeh, R. Y. Mashouf, and H. Mortazavi, "Antibacterial and antifungal activities of Punica granatum peel extracts against oral pathogens," Journal of Dentistry, vol. 8, pp. 1-6, 2011.

[47] S. Das and S. Barman, "Antidiabetic and antihyperlipidemic effects of ethanolic extract of leaves of Punica granatum in alloxan-induced non-insulin-dependent diabetes mellitus albino rats," Indian Journal of Pharmacology, vol. 44, no. 2, pp. 219-224, 2012.

[48] M. A. Dkhil, "Anti-coccidial, anthelmintic and antioxidant activities of pomegranate (Punica granatum) peel extract," Parasitology Research, vol. 112, no. 7, pp. 2639-2646, 2013.

[49] J. G. El Diasty, M. M. Hassan, and O. M. Kamal, "Evaluation of some agricultural waste extracts against mosquito larvae, and some types of microorganisms as insecticidal and antibiotic agents," Egyptian Academic Journal of Biological Sciences, vol. 6, pp. 1-16, 2014.

[50] M. A. Tantray, S. Akbar, R. Khan, K. A. Tariq, and A. S. Shawl, "Humarain: a new dimeric gallic acid glycoside from Punica granatum L. bark," Fitoterapia, vol. 80, no. 4, pp. 223-225, 2009.

[51] A. Vidal, A. Fallarero, B. R. Peña et al., "Studies on the toxicity of Punica granatum L. (Punicaceae) whole fruit extracts," Journal of Ethnopharmacology, vol. 89, no. 2-3, pp. 295-300, 2003. 


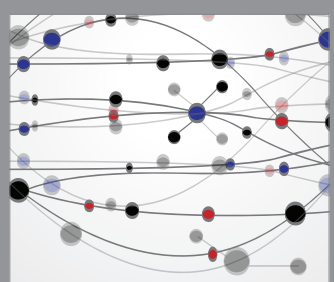

The Scientific World Journal
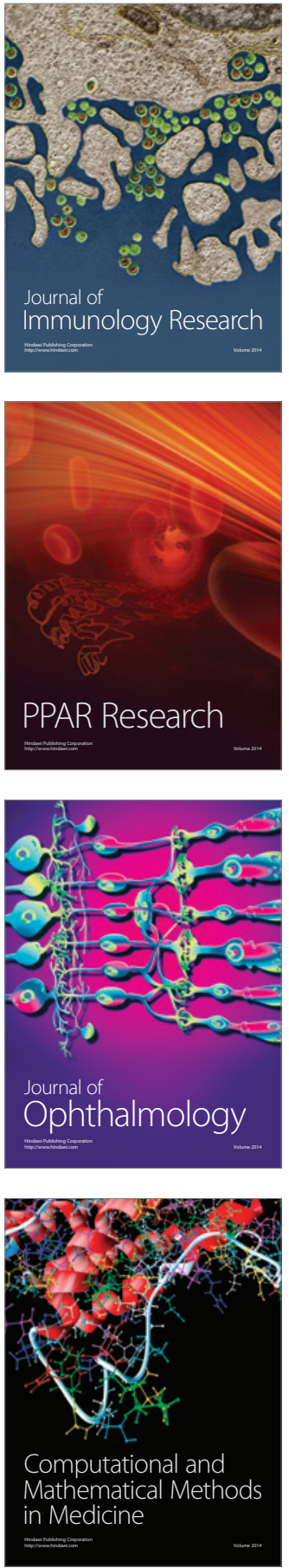

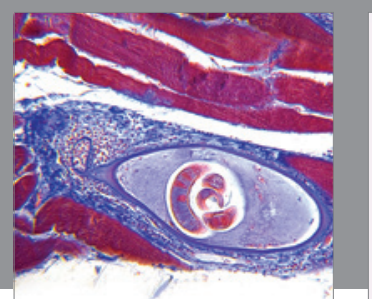

Gastroenterology Research and Practice

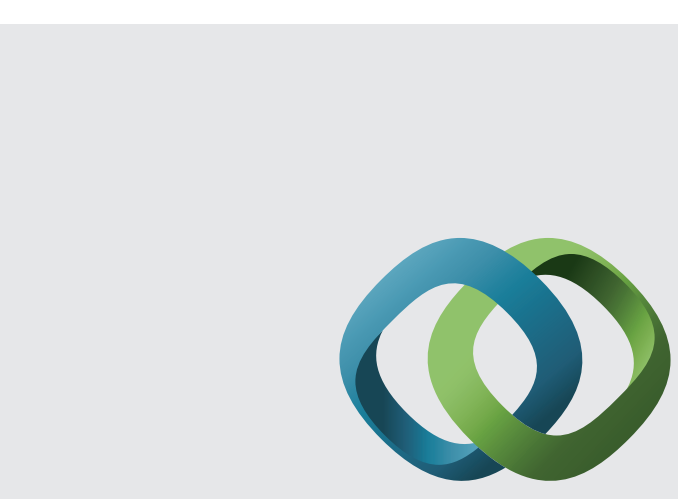

\section{Hindawi}

Submit your manuscripts at

http://www.hindawi.com
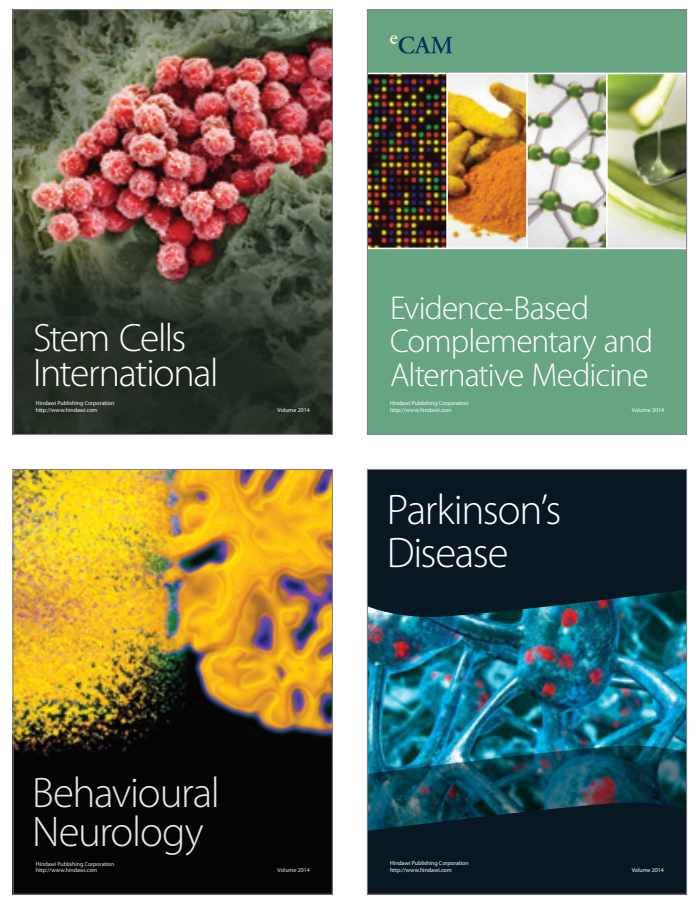
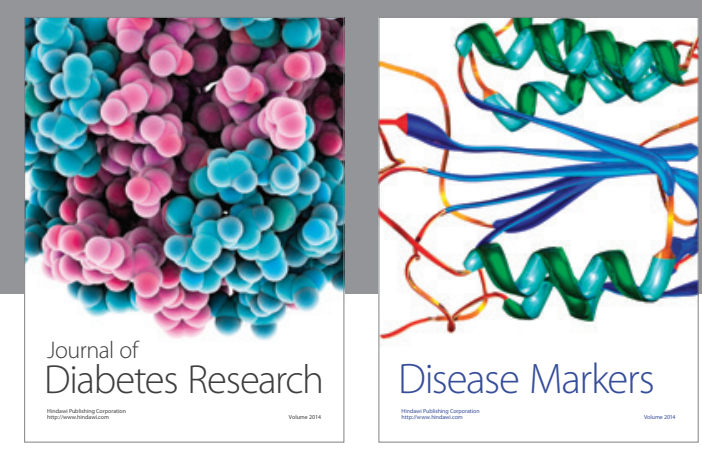

Disease Markers
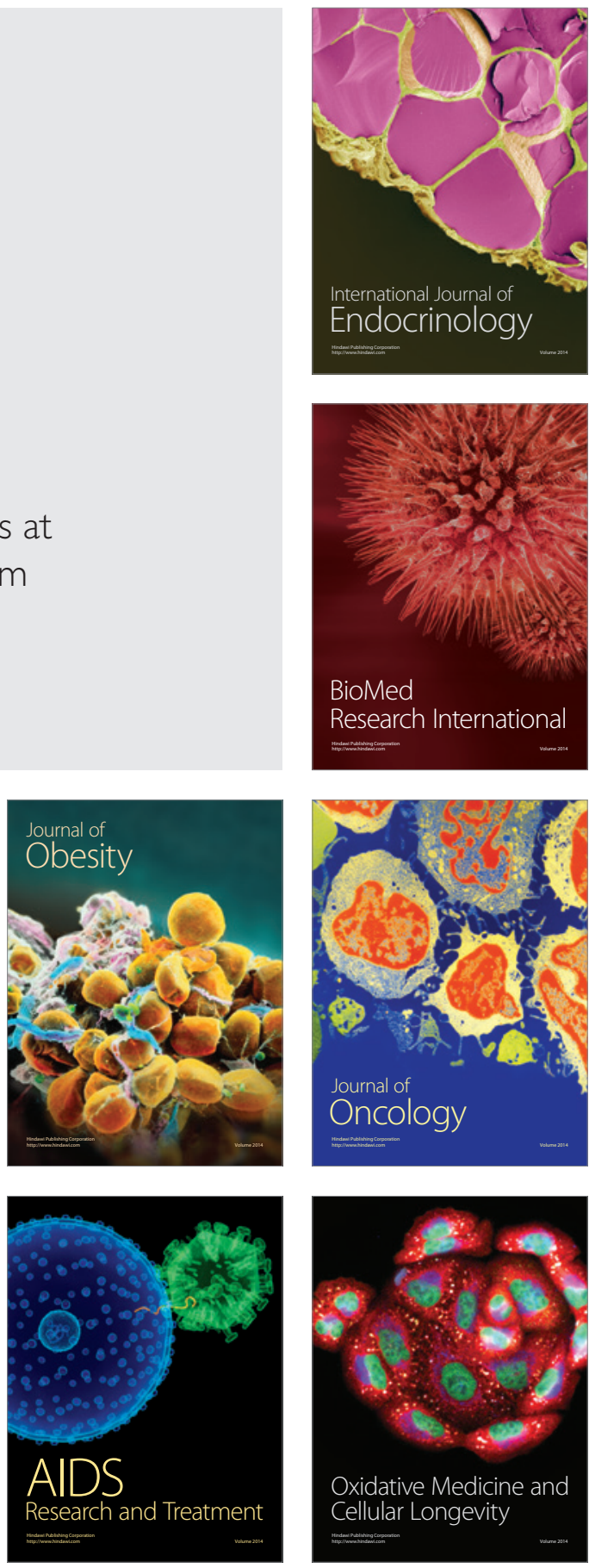